\title{
Educação ambiental relacionada à coleta de resíduos sólidos contaminantes produzidos na Universidade Federal do Piauí
}

\section{Ranes Batista da Rocha ${ }^{1}$, Johnny Iglesias Mendes Araujo ${ }^{2 *}$, Sergio Luiz Carvalho Santos ${ }^{\mathbf{1}}$, James Batista da Rocha ${ }^{3}$, Ana Lucia Alves da Silva ${ }^{4}$, Gilvan Rodrigues dos Santos ${ }^{5}$, Joniel Mendes de Araujo ${ }^{6}$}

\footnotetext{
${ }^{1}$ Liceciatura em Ciências Biológicas/UFPI- Campus Prof. ${ }^{a}$ Cinobelina Elvas, Bom Jesus, Piauí, Brasil. E-mail: ranes.ufpi@hotmail.com; sergioluizcrvlh@gmail.com

${ }^{* 2}$ Mestrando em Zootecnia pela Universidade Federal do Piauí, Campus professora Cinobelina Elvas, Departamento de Zootecnia, Bom Jesus, Piauí, Brasil. E-mail: Johnny-iglesias@ hotmail.com

${ }^{3}$ Graduando em Direito/UESPI - Dom José Vasquez Dias, Bom Jesus, Piauí, Brasil. E-mail: ja.mes-ufpi@ hotmail.com

${ }^{4}$ Especialista em Docência e Supervisão Escolar (IESM), Timon, Maranhão, Brasil. E-mail: anaufpi@ hotmail.com

${ }^{5}$ Mestrando em Ciências da Educação e Multidisciplinaridade/FACNORTE. Gmail: gr.seduc.pi@gmail.com

${ }^{6}$ Mestrando em Ciências Biológicas, Universidade Federal do Goiás, Campus Samambaia, Departamento de Biologia, Goiânia, Goiás, Brasil. E-mail: niel-ma30@hotmail.com

*Autor para correspondência
}

RESUMO. Este trabalho teve como proposta, por meio dos resultados encontrados, discutir os principais impactos ambientais que os resíduos contaminantes podem causar, e procurar saber se a população acadêmica está ciente do trabalho realizado pela instituição dentro do campus CPCE (Campus professora Cinobelina Elvas). O presente trabalho foi realizado na Universidade Federal do Piauí (UFPI), Campus Professora Cinobelina Elvas/CPCE na cidade de Bom Jesus/PI. Para levantamento da coleta de dados utilizou-se entrevista com dez estudantes, três professores, sendo eles dos Cursos de Licenciatura em Ciências Biológicas, Engenharia Florestal, Zootecnia e cinco funcionário do CPCE. A entrevista baseou-se por meio de questionário com abordagens diretas ao assunto. Quando questionados se o trabalho realizado pela Universidade pode proporcionar alguma mudança no campus, $100 \%$ dos entrevistados responderam "sim". Em relação aos professores interrogados se a UFPI faz coleta de resíduos contaminantes, $66,67 \%$ das respostas foram "sim". Já em relação aos funcionários que se dispuseram a responder o questionário, 100\% respondeu "sim" para a mesma pergunta. Portanto, o trabalho discute acerca dos principais impactos ambientais causados pela deposição indevida de resíduos sólidos com potencial contaminante e aponta tambem soluções de problemas ambientais causados por resíduos perigosos com metais pesados.

Palavras chave: Coleta seletiva, educação ambiental, impactos ambientais

\section{Environmental education relating to solid contaminants waste collection produced in the Federal University of Piauí}

\begin{abstract}
This work was proposed by means of the results, discuss the main environmental impacts that contaminants can cause waste, and to whether the academic population is aware of the work done by the institution within the CPCE campus. This study was conducted at the Federal University of Piauí (UFPI), Campus Professor Cinobelina Elvas/CPCE in Bom Jesus/PI. For survey data collection was used interviews with ten students, three teachers, and they of Degree Courses in Biological Sciences, Forestry, Animal Husbandry and five employee CPCE. The interview was based on a questionnaire with direct approaches to the subject. When asked if the work done by the University may provide some change on campus, $100 \%$ of respondents answered "yes." Regarding the teachers interrogated the UFPI is collecting toxic residues, $66.7 \%$ of the answers were "yes." In relation to employees who agreed to answer the questionnaire, $100 \%$ answered "yes" to the same question. Therefore, the paper discusses about the main
\end{abstract}


environmental impacts caused by improper disposal of solid waste with potential contaminant and also highlights environmental problem solutions caused by hazardous waste with heavy metals.

Keywords: selective collection, environmental education, environmental impacts

\section{Introdução}

$\mathrm{O}$ meio ambiente tem sofrido grandes consequências devido ao aumento desordenado do lixo produzido na zona urbana. As cidades não possuem um planejamento adequado para ocupação acentuada de grandes massas sociais, há então distribuição e ocupação inadequadas do espaço urbano (Diegues, 1997). Assim, um dos principais fatores que contribui direto com isso, refere-se ao grande avanço tecnológico juntamente com crescimento desorganizado da população mundial, que por sua vez não investe em planejamento e em estrutura que poderia evitar tais impactos negativos.

Nos últimos anos, em plena era de modernizações, a maioria das pessoas tem passado a habitar nas cidades. Os dados apresentados pelo Instituto Brasileiro de Geografia e Estatística (IBGE, 2010), indicam que o Brasil ultrapassou a marca de $85 \%$ de pessoas que residem em áreas urbanas. Com tudo isso, obviamente o que se ver, é a problemática de resíduos atingindo milhares de pessoas, principalmente aquelas que vivem nas cidades mais desenvolvidas.

O consumo tem aumentado devido ao surgimento em grande escala de aparelhos tecnológicos, equipamentos eletrônicos que tem despertado a ansiedade das pessoas a utilizarem de forma descontrolável, pois a cada momento surgem novos modelos e apelos para novas aquisições, principalmente nos países mais desenvolvidos.

Os materiais contaminantes como pilhas, baterias, lâmpadas e outros tem grande influencia quando estão expostos ao meio ambiente, pois liberam substancias que contaminam a água que penetra no solo atingindo os rios, riachos e lençois freaticos causando serios riscos para o meio e para a saúde humana. Neste sentido a melhor maneira de proteger e de evitar a contaminação do meio ambiente é sensibilizar as pessoas a jogar os residuos perigosos corretamente em seus lugares adequados. Todas essas práticas habituais das pessoas junto com as águas das chuvas provocam grandes impactos ambientais como as contaminações dos rios, solo, lençois freaticos, plantações e tambem seres vivos como peixes por viver em água poluida por esses metais pesados.

Objetivou-se com esta pesquisa, por meio dos resultados encontrados, discutir os principais impactos ambientais que os resíduos contaminantes podem causar, e procurar saber se a população acadêmica está ciente do trabalho de coleta realizado dentro do campus professora Cinobelina Elvas.

\section{Material e Métodos}

O presente trabalho foi realizado na Universidade Federal do Piauí (UFPI), Campus Professora Cinobelina Elvas/CPCE na cidade de Bom Jesus/PI. Localizado a uma latitude de $09^{\circ}$ $04^{\prime}, 28^{\prime}$ ' sul e a uma longitude de $44^{\circ} 21^{\prime}, 31^{\prime}$ ' oeste, estando a uma altitude de 277 metros, possui uma área de $5.469 \mathrm{~km}^{2}$, a $635 \mathrm{Km}$ de distância da Capital Teresina-PI. A cidade é referencia no desenvolvimento do agronegócio, nos setores de comércio, indústria e serviços. Alem de congregar frequentemente habitantes de cidades circunvizinhas na resolução de negocios.

Os resíduos contaminantes descartados no Campus da Universidade Federal do Piauí (UFPI) foram: lampadas, baterias e pilhas que contém grande concentração de metais pesados como mercurio, cadmio, chumbo, zinco e outros. Estes são coletados seletivamente pela instituição, que os recolhe para serem destinados em um local adequado. A Universidade não realiza o descarte final desses objetos em momento algum. Mas um contrato da UFPI com uma empresa responsável e ciente dos danos que estes podem causar ao meio ambiente, faz com que esse lixo seja recolhido e direcionado a um lugar correto.

Para conhecer o destino dado aos resíduos que possuem grande concentração de metais pesados coletados na UFPI, foram realizadas por meio de entrevistas com dez estudantes denominados de "E", três professores de "P" sendo eles dos Cursos de Zootecnia, Engenharia Florestal e Ciências Biológicas e também com cinco funcionários de "F", sendo um deles o responsável pela parte elétrica do campus. Elaboraram-se, três roteiros de entrevistas com pequenas diferenças entre eles que foram aplicados para os distintos públicos do 
campus (CPCE). As identidades dos sujeitos entrevistados não foram reveladas garantindo assim, o anonimato. A pesquisa dos dados foi realizada durante o $1^{\circ}$ semestre do ano de 2014.

As entrevistas foram realizadas através de questionários relacionados com as coletas de resíduos sólidos contaminantes produzidos pela UFPI/CPCE. Os questionários voltados para a entrevista com os alunos se deu por meio das seguintes perguntas: 1) Você já observou que a UFPI faz coleta de resíduos que tem concentração de metais pesado dentro do campus?; 2) O que você tem a dizer desse trabalho que está sendo feito pela universidade?; 3) Você tem ideia onde são jogados esses resíduos coletados aqui no campus?; 4) Você acha que esse trabalho realizado pela universidade pode mudar alguma coisa no campus? o que?; 5) De que maneira você pode contribuir com esse trabalho realizado pela universidade federal do Piauí (UFPI)?; 6) De acordo com o seu conhecimento, de que maneira devem ser acondicionados esses tipos de resíduos?; 7) Que tipo de problemas esses materiais pode causar se forem destinados de forma inadequada?; 8) De que maneira esse trabalho é visto por você como estudante do campus?; 9) Já ouviu falar ou conhece a política nacional dos resíduos sólidos?.

Os questionários voltados para os funcionários foram: 1) Você sabia que a UFPI faz coleta de resíduos sólidos? Quais são eles?; 2) Você sabe dizer qual a importância disso?; 3) Você sabia que alguns deles podem contaminar a água e o solo?; 4) Você sabe para onde são levadas essas lâmpadas, pilhas e baterias coletadas na universidade?; 5) De que maneira são destinados esses resíduos?; 6) Você tem conhecimento do que esses tipos de resíduos podem causar tanto pro meio ambiente quanto pra saúde da população?; 7) De que maneira você pode contribuir com esse trabalho realizado pela universidade federal do Piauí (UFPI)?; 8) De que maneira esse trabalho é visto por você como funcionários do campus?; 9) De acordo com o seus conhecimentos como deve ser tratado esse tipo de resíduos?

Já os questionários para as entrevistas com professores foram: 1) Você sabia que a UFPI faz coleta de resíduos contaminantes?; 2) Você acha que de alguma forma a coleta desses resíduos contaminantes vai mudar a atitude das pessoas que convivem diariamente no campus da universidade? por quê?; 3) Em relação a coleta dos resíduos contaminados o que você espera desse trabalho desenvolvido pela UFPI?; 4) De que maneira esse trabalho é visto por você como professor do campus?; 5) Além do que estar sendo feito, você sugeria algo melhor ou diferente na realização das coletas desses materiais dentro da universidade?; 6) Que tipo de tratamento deve se dar a esses tipos de resíduos?; 7) Se for manejada de forma inadequada, quais perigos podem trazer para o meio ambiente e para saúde das pessoas?; 8) tem ideia para onde são destinados esses resíduos coletados aqui no campus?; 9) você já observou algo de errado na realização da coleta dos materiais contaminantes dentro da universidade? o que?

\section{Resultados e Discussão}

Os resultados obtidos durante as entrevistas foram bastante positivos e claros. Sendo assim, a seguir serão apresentados resultados mais expressivos obtidos nas entrevistas com os participantes envolvidos, onde temos:

\section{Estudantes}

Aos estudantes quando perguntados, se a UFPI faz coleta de resíduos de materiais com metais, dentro do campus, 8 responderam que "sim" representando $80 \%$ dos entrevistados.

Sobre o trabalho que está sendo feito pela Universidade, 3 respostas mencionaram ser favoráveis ao "cuidado e a iniciativa". Destacamse as seguintes opiniões, por serem consideradas representativas.

" $R$ = 5- Tenho uma boa impressão que a (UFPI) está preocupada com as gerações futuras, ou seja, não estão poluindo o meio ambiente, está tentando melhorar o nosso espaço."

" $\mathrm{R}=8$ - Acho muito importante, pois evita que os mesmos sejam jogados a céu aberto em lixões."

" $\mathrm{R}=9$ - Esse trabalho é muito importante dentro do campus, pois afasta dos perigos que esses resíduos podem causar e também serve de incentivo para outras Universidades."

Por estar de acordo com a Lei Nacional dos Resíduos Sólidos no Art. $3^{\mathrm{o}}$ entende-se por disposição final ambientalmente adequada aquilo ordenada de rejeitos em aterros, observando normas operacionais específicas de modo a evitar danos ou riscos à saúde pública e à segurança e a minimizar os impactos ambientais adversos.

Quando questionados se o trabalho realizado pela Universidade pode mudar alguma coisa, em 
$100 \%$ das respostas obtivemos "sim". Das quais se destacam:

"R = 5 - Sim, por que é daí que começa. De um simples fato, pode-se desenvolver outra prática de recolhimento do lixo do nosso campus."

" $\mathrm{R}=7$ - $\mathrm{O}$ que faz uma pessoa mudar de opinião não é a lei nem muito menos prisão, mais sim a educação pessoal por meio da conscientização. Tendo em vista o trabalho realizado pela Universidade pode mudar a consciência dos jovens, além de manter o campus limpo e com uma boa qualidade."

De acordo com Jacobi et al. (1998) pode-se dizer, portanto, que a educação para cidadania deve desenvolver-se para a formação de sujeitos cidadãos servindo-se da educação ambiental como um instrumento de transformação social.

Sobre a maneira de contribuir com o trabalho realizado pela Universidade, 4 responderam "a comunicação no campus", e 5 "contribuindo para o destino adequado".

Quando se perguntou de que maneira devem ser acondicionados, apenas 6 mencionaram "fechados de maneira adequada" e 3 responderam que "devem ser separados dos demais resíduos".

Ao questionar sobre os tipos de problemas que estes materiais podem causar se for destinado de forma incorreta, 8 responderam "poluição do meio ambiente" sendo equivalente a $80 \%$ dos entrevistados, entre eles podem destacar-se:

"R = 3 - Poluição no meio ambiente e causas de varias doenças."

" $\mathrm{R}=5$ - Pode causar a poluição da natureza, a poluição do ar, do solo, e por fim causar mal a nossa saúde."

Art. 7ํㅗ̃o objetivos da Política Nacional de Resíduos Sólidos:

I - Proteção da saúde pública e da qualidade ambiental;

V - Redução do volume e da periculosidade dos resíduos perigosos;

Perguntado sobre a maneira de o trabalho ser visto (por você como estudante), 4 respostas mencionaram ser "importante", por serem consideradas destacam-se as seguintes opiniões representante. E os outros 6 entrevistados comentaram sobre conscientização, combater a irregularidade, satisfatória, organizada, excelente, boa iniciativa.

" $R=8-$ É de suma importância, pois contribui com o meio ambiente".
" $R=9-E$ visto como uma importante forma de planejamento para outros trabalhos com o mesmo objetivo que darão mais vigor a essa iniciativa".

A Educação Ambiental na Universidade "conduz os profissionais a uma mudança de comportamento e atitudes em relação ao meio ambiente interno e externo das suas organizações", despertando o interesse em cada funcionário na "ação e busca de soluções concretas para os problemas ambientais que ocorrem principalmente no seu dia-a-dia" (Vieira, 2003).

Em relação a perguntar se já ouviu falar ou conhece a Política Nacional dos Resíduos Sólidos, 5 respostas que "não" e 4 que "sim".

\section{Funcionários}

Aos serem questionados sobre a questão se a UFPI faz coleta de resíduos sólidos, $100 \%$ das respostas foram "sim".

Em relação a ser perguntado qual a importância disso, obteve-se 4 respostas que mencionaram "a importância com o meio ambiente", entre elas destacam-se.

" $\mathrm{R}=2$ - Para evitar a contaminação do meio ambiente".

" $\mathrm{R}=4$ - A importância é que não vai poluir o meio ambiente".

Brasil (1988), art. 225 há a seguinte frase: Todos têm direito ao meio ambiente ecologicamente equilibrado, bem de uso comum do povo e essencial à qualidade de vida impondose ao Poder público e à coletividade o dever de defendê-lo e preservá-lo para os presentes e futuras gerações.

Quando perguntados se algum deles pode contaminar a água e o solo, 4 responderam "sim", equivalendo $80 \%$ dos entrevistados.

Quando questionados para onde são levadas as lâmpadas, pilhas e baterias coletados na Universidade, 4 respostas foram "não", obtendo $80 \%$ dos entrevistados.

Sobre a maneira como são destinados esses resíduos, 2 responderam para a "lixeira" e 2 "não sabe", apenas 1 mencionou para Teresina.

Sobre ter conhecimento do que esses tipos de resíduos pode causar tanto pro meio ambiente quanto pra saúde da população, 3 respostas mencionaram "diversos tipos de doenças". 
Quando se questionou de que maneira pode contribuir com esse trabalho realizado pela Universidade $100 \%$ das respostas mencionadas são favoráveis "a colocar em lugares adequados" entre elas destacam-se

" $\mathrm{R}=2$ - Jogar os materiais nos lugares adequados".

" $\mathrm{R}=3$ - Contribuindo com a UFPI a colocar em lixeira adequada".

\section{Seção II}

Do Plano Nacional de Resíduos Sólidos Art. 15. III - metas de redução, reutilização, reciclagem, entre outras, com vistas a reduzir a quantidade de resíduos e rejeitos encaminhados para disposição final ambientalmente adequada.

Questionando sobre de que maneira o trabalho é visto pelos funcionários, 4 dos entrevistados mencionaram a "importância do trabalho".

Sobre o conhecimento, como deve ser tratado os resíduos, 3 respostas são a favor da reciclagem, sendo equivalente a $60 \%$ dos entrevistados, entre elas destacam 2 opiniões representativas.

" $\mathrm{R}=1$ - Deve ser reciclado, pois temos consciência do que pode causar para o meio ambiente."

" $\mathrm{R}=5$ - Através da coleta deve ser destinado a um ambiente adequado, onde possa ser tratado corretamente ou se for o caso pode até ser reciclado".

De acordo com Rodrigues (1998), a preservação ou conservação da natureza tem na reutilização, na reciclagem, uma forma de conter o desperdício de materiais e fontes de energia contida no lixo acumulado ou queimado em incineradores. Ou seja, é uma mercadoria que tanto é fator de degradação do lugar onde se encontra acumulado, como é (ou pode ser) fator de economia com reutilização e reciclagem.

\section{Professores}

Quando perguntados se a UFPI faz coleta de resíduos contaminantes, $66,67 \%$ das respostas foram "SIM".

Ao questionar saber se a coleta desses resíduos contaminantes muda a atitude das pessoas que vivem diariamente no campus, $100 \%$ das respostas afirmam "sim, mudar a consciência". Por ser assim destacam as representativas respostas.

" $\mathrm{R}=2$ - Sim, acabam ficando conscientizados."
" $\mathrm{R}=3$ - A mudança de atitude é um processo lento, acredito eu. No entanto se esta insiste atingir um mínimo possível de pessoas já é valida, mudar a atitude faz-se necessário, mudar a consciência, e isso é uma questão de educação também."

Para Meyer (1991), a Educação Ambiental não é vista como uma solução "mágica" é um processo contínuo de aprendizagem, de conhecimento e exercício da cidadania, que capacita o indivíduo a ter uma visão crítica da realidade e uma atuação no espaço social.

Ao questionar-se sobre a coleta dos resíduos contaminantes, e o que se espera do trabalho da Universidade, todas as respostas são favoráveis "a ter consciência com o meio ambiente", destacamse as seguintes opiniões.

" $\mathrm{R}=1$ - Espero que a UFPI siga as relações normativas do CONAMA e que tratem esse lixo, e na verdade acompanhe a empresa que coleta esse lixo pra que não seja jogado a céu aberto".

" $\mathrm{R}=2$ - Que melhore a conscientização das pessoas e evite a contaminação do meio ambiente".

A resolução Conama ${ }^{\circ} 257$, (de 30.06.99), que aborda os impactos ambientais negativos devido ao descarte inadequado de pilhas e baterias usadas e trata de sua disposição final. O Art. $13^{\circ}$ da Resolução Conama 257/99. Porém, devido ao volume e à velocidade de geração desses resíduos, o seu descarte inadequado pode representar graves danos ambientais e sanitários, uma vez que em sua composição estão presentes outros metais pesados e substâncias tóxicas.

Sobre a relação de o trabalho ser visto pra eles como professo da Universidade, $100 \%$ das respostas dos entrevistados foi, "bem vindo" e uma "boa iniciativa".

Ao perguntar se sugeria algo melhor na coleta dos materiais dentro da Universidade, 2 respostas acham que tem que "melhorar mais", equivalendo a $66,67 \%$ das opiniões, sendo consideradas representativas.

" $\mathrm{R}=1-$ Sim, eu acho que a UFPI tinha que ter um processo de coleta seletiva mais robusta".

" $R=3$ - A coleta é meio improvisada, aproveitando recipientes que normalmente são usados para outros fins. Sugeria que fossem usados coletores apropriados e uma campanha no campus".

Fuzaro (2001) afirma que, coleta seletiva de lixo é um processo que consiste na separação e 
recolhimento dos resíduos descartados por empresas e pessoas. Questionando sobre o tipo de tratamento que se da a esse tipo de resíduo, 2 respostas obtida diz que "cada tipo de resíduo deve ser tratado conforme ele seja". Perguntou-se em relação o manejo inadequado, e os perigos que estes podem trazer pro meio ambiente e a saúde, todas as respostas são favorecida ao "meio ambiente" e a "saúde". Equivalendo $100 \%$ das opiniões obtidas. Destacam-se as seguintes opiniões.

" $\mathrm{R}=1-\mathrm{O}$ manejo inadequado desses resíduos pode provocar no meio ambiente a contaminação do solo, rios e lençóis freáticos e também serem causas de doenças. A exposição das pessoas em ambientes onde são jogados vários tipos resíduos contaminantes ou não pode ocorrer doenças transmitidas por animais nocivos. Além disso, o volume do lixo tratado prejudica a demanda do planejamento urbano".

" $\mathrm{R}=2$ - Podem contaminar o meio ambiente e causar doenças graves".

Como diz Rodrigues (1998), caracterizam-se pela simples descarga dos resíduos sólidos. Acarretam vários problemas à saúde, com proliferação de moscas, baratas, ratos etc., geração de mau cheiro, do chorume, contaminação do solo e das águas superficiais e subterrâneas.

Sobre onde são destinados os resíduos coletados na universidade, $100 \%$ dos entrevistados responderam "que não sabe".

Quando questionados sobre algo de errado na coleta dos materiais contaminantes na universidade, 2 respostas opinaram dizendo que não tem coletores adequados. Por considerar representativa, destacam-se.

" $\mathrm{R}$ = 1 - Laboratório como o de Zoologia: não possui coletores adequados para a recepção de materiais perfuro cortantes. Sendo assim dispostos esses resíduos junto com outros menos perigosos".

" $\mathrm{R}=3$ - Acredito que seria a mistura dele, ou seja, todos nos mesmos coletores, além de ser acessíveis a todos os indivíduos do CPCE".

Os tipos de recipientes variam de acordo com o sistema de coleta seletiva implantado; e com a disposição dos recursos financeiros envolvidos para realização do programa. Esses recipientes possuem uma padronização já estabelecida, ou seja, a cor verde para o vidro, a azul para o papel, a vermelha para o plástico, e a cor amarela para os metais (D’Almeida \& Vilhena, 2000).

\section{Considerações finais}

O trabalho discute acerca dos principais impactos ambientais causados pela deposição indevida de resíduos sólidos com potencial contaminante e aponta tambem soluções de problemas ambientais causados por resíduos perigosos com metais pesados. E relata a maneira como deve ser destinado corretamente o lixo sem provocar danos à saúde do homem e ao meio ambiente.

O meio ambiente tem sofrido grandes impactos causados pela falta de consciência e conhecimento do homem com os danos ambientais, e também à ausência de tratamento ou destinação incorreta do lixo produzido nas cidades.

$\mathrm{O}$ homem às vezes não percebe que é parte integrante do meio ambiente, por isso acaba destinando o lixo de forma errada por não conhecer a maneira correta de dar destino aos mesmos, sendo que muita das vezes nem percebe que passa a sofre as consequências destas praticas.

Bom Jesus é um exemplo: não possui nenhum método de coleta seletiva, aterro sanitário, tratamento de esgoto, ou até mesmo empresas que separem, reutilize ou reciclem o lixo. Todos os resíduos tóxicos são usados e descartados junto com os demais tipos de lixo gerados na cidade, e jogados a céu aberto provocando problemas ambientais, principalmente nos períodos chuvosos.

As mudanças ocorridas nos últimos tempos mostram que as consequências são causadas por falta de conhecimento, informações e até mesmo orientação adequada para as pessoas sobre os cuidados necessários que devem ser tomadas nas horas de descartes do lixo produzido.

Para evitar todos os tipos de tragédia no meio ambiente e na vida do homem, é preciso fazer a coleta seletiva e a separação dos resíduos contaminantes em vasilhames específicos, com a contribuição de toda população a depositar seu lixo nos lugares corretos pra ser direcionado a um local bem seguro. Pois resíduos como estes devem ser separados dos demais lixos e depositados em contêiner especifico para pilhas, baterias, reatores e lâmpadas. Esse tipo de resíduos depois de coletado deve ser direcionado a um local onde possa ser armazenados em estruturas feitas de concreto bem resistente, impedindo a infiltração do liquido destes objetos, depois de depositado dentro da estrutura eles deve ser lacrado com 
tampa de cimento onde deve permanecer sempre fechados.

\section{Referências Bibliográficas}

Brasil. 1988. Constituição da República Federativa do Brasil. Título VIII - Da Ordem Social, Capítulo VI - Do Meio Ambiente (art. 225).

Brasil. Universidade Federal do Piauí (2010). Conheça o programa de reestruturação e expansão das Universidades Federais. Disponível em: <http://www.ufpi.br/reuni/noticia.php?id=4> Acesso em: 05 de agosto de 2014.

Conama - Resolução no 257 de 30 de junho de 1999 - Diário Oficial da União - Brasília, 22 de julho de 1999.

D’Almeida, M. L. O. \& Vilhena, A. 2000. Lixo Municipal: Manual de Gerenciamento Integrado. São Paulo: IPT/CEMPRE, p. 370.

Diegues, A. C. (1997). O Mito do paraíso desabitado nas florestas tropicais brasileiras. In: Castro, E. \& Pinton, F. (Orgs). Faces do trópico húmido: Conceitos e questões sobre desenvolvimento e meio ambiente. Cejup, UFPA/NAEA, Belém, Brasil, 446p.

Fuzaro, J. A. (2001). CETESB - Companhia de Tecnologia de Saneamento Ambiental -
Compêndio sobre tratamento e disposição de resíduos sólidos. São Paulo.

IBGE- Instituto Brasileiro de Geografia e Estatística. 2010. Disponível em <http://www.ibge.com.br>

Jacobi, P. 2003. Educação Ambiental, Cidadania e Sustentabilidade. Cadernos de Pesquisa, 118, 189-205.

Meyer, M. A. D. A. 1991. Educação Ambiental: uma proposta pedagógica. Em Aberto, Brasília, v. 10, n. 49.

Rodrigues, A. M. 1998. Produção e Consumo do e no Espaço: problemática ambiental urbana. São Paulo: Hucitec.

Vieira, L. 2003. O papel da educação ambiental em empresas. Revista Eletrônica do Instituto de Educação Tecnológica. Belo Horizonte

\section{Article History:}

Received 14 September 2016

Accepted 10 October 2016

Available on line 29 November 2016

License information: This is an open-access article distributed under the terms of the Creative Commons Attribution License 4.0, which permits unrestricted use, distribution, and reproduction in any medium, provided the original work is properly cited. 